\title{
LA NATURALESA JURIDICA DEL DERECHO EDUCATIVO
}

\author{
A LEI DE EDUCAÇÃO JURÍDICA NATURAL
}

THE NATURAL JURIDICAL EDUCATION LAW

\author{
Raúl Edilberto Soria Verdera ${ }^{1}$
}

\begin{abstract}
Resumen
Se quiere dar énfasis a la compleja relación entre derecho, educación y sociedad..Con el término "construcción", se quiere destacar el carácter dinámico e histórico del Derecho Educativo, poniendo en evidencia que no es algo terminado o construido para siempre donde lo permanente permanece estático y lo mudable parece consumir y agotar lo permanente. También ayuda a comprender mejor lo jurídico en un marco de referencia más orientador que lo integra a una concepción de la educación, a fin de que derecho y educación no aparezcan como ámbitos separados, sino unidos en una realidad natural y social. Un rasgo distintivo del Derecho Educativo y los derechos humanos es que ellos versan sobre principios naturales de fundamental importancia para la sociedad. No existe derecho alguno por encima del Derecho Educativo, es el derecho de los derechos y es primordial para el ejercicio de los derechos humanos.El Derecho Educativo tiene una importancia primordial para la sociedad actual.
\end{abstract}

Palabras clave: Derechos humanos. Educación. La sociedad.

\section{Resumo}

Queremos enfatizar a relação complexa entre direito, educação e sociedade. Com o termo "construção", queremos destacar a natureza dinâmica e histórica da Lei Educacional, mostrando que não é algo acabado ou construído para sempre, onde a permanente permanece estático e o mutável parece consumir e exaurir a permanente. Ela também ajuda a entender melhor o sistema jurídico em um quadro de referência que integra mais guiando-o a uma concepção de educação, de modo que a lei de educação e não pode aparecer como áreas separadas, mas unidos em uma realidade natural e social. Uma característica distintiva do Direito Educacional e dos direitos humanos é que eles lidam com princípios naturais de importância fundamental para a sociedade. Não há certo acima da Lei de Educação é a lei dos direitos e é essencial para o exercício dos direitos humanos. A Educação é de suma importância para a sociedade de hoje.

Palavras-chave: Direitos humanos. Educação. Sociedade.

\section{Abstract}

We want to emphasize the complex relationship between law, education and society .. With the term "construction", we want to highlight the dynamic and historical nature of the Educational Law, showing that it is not something finished or built forever where the permanent it remains static and the mutable seems to consume and exhaust the permanent. It also helps to better understand the legal aspect in a more guiding frame of reference that integrates it into a conception of education, so that law and education do not appear as separate areas, but united in a natural and social reality. A distinctive feature of Educational Law

\footnotetext{
${ }^{1}$ Presidente RIIDE Argentina.
}

\begin{tabular}{l|l|l}
\hline Rev. Ciências Humanas & Frederico Westphalen, RS & Jan./abr. 2019 \\
\hline
\end{tabular}

\begin{tabular}{l|l|l} 
Recebido em: 27/02/2019 & Aceito em: 26/04/2019 & Pg. $154-159$
\end{tabular}




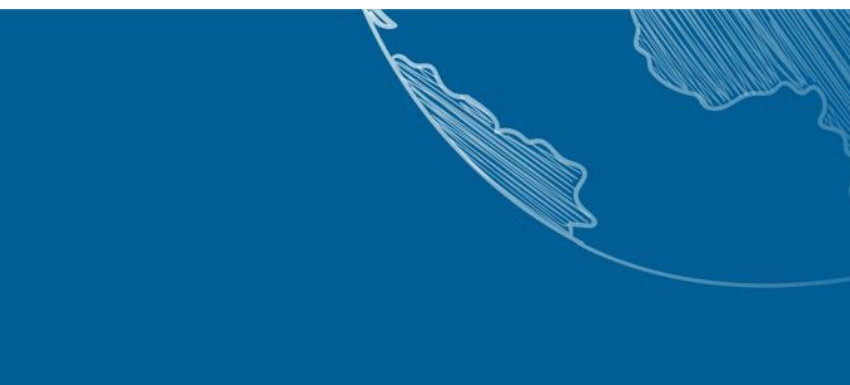

and human rights is that they deal with natural principles of fundamental importance to society. There is no right whatsoever above Educational Law, it is the right of rights and it is essential for the exercise of human rights. The Educational Right is of paramount importance for today's society.

Keywords: Human rights. Education. Society.

\section{INTRODUCCIÓN}

Al referirse a la construcción jurídica del Derecho Educativo se quiere dar énfasis a la compleja relación entre derecho, educación y sociedad.

Con el término “construcción”, se quiere destacar el carácter dinámico e histórico del Derecho Educativo, poniendo en evidencia que no es algo terminado o construido para siempre donde lo permanente permanece estático y lo mudable parece consumir y agotar lo permanente.

También ayuda a comprender mejor lo jurídico en un marco de referencia más orientador que lo integra a una concepción de la educación, a fin de que derecho y educación no aparezcan como ámbitos separados, sino unidos en una realidad natural y social.

Además, facilita integrar lo jurídico en una concepción de la naturaleza humana que afirma y expresa, por un lado, la unidad y universalidad del género humano y sus posibilidades de perfeccionamiento y de realización, y por otro descubrir e investigar la dimensión natural, histórica y social del hombre.

Esperamos que este enfoque permita captar y comprender lo esencial y lo específico de lo jurídico en la educación, así como los grados de complejidad y desarrollo de los niveles de reflexión alcanzados en las distintas fases del Derecho Educativo.

Es fácil advertir entonces que se están abriendo nuevas y distintas perspectivas de investigación y análisis, y que son muchas las manifestaciones de los cambios sociales, científicos y tecnológicos con consecuencias en el Derecho Educativo.

Tales hechos son más bien un estímulo para buscar nuevos caminos que pongan el centro de interés en el Derecho Educativo, en un mundo especializado y pragmático.

Son muchas las dificultades y limitaciones de este intento, pero también es cierto que es un momento propicio para plantear los problemas propios de la inspiración, definición de las funciones, contenido y objeto del Derecho Educativo. 


\section{CIÊNCIAS HUMANAS}

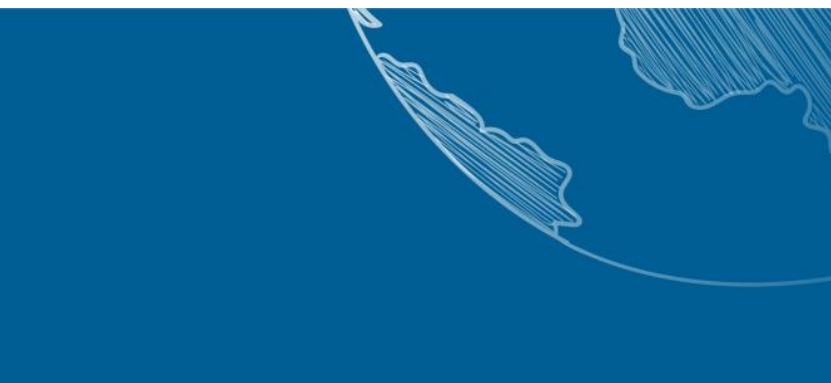

Por eso, esta propuesta que formulamos, intenta despertar la conciencia del largo y complejo proceso de formación y transformación del Derecho Educativo, su presente y futuro, las experiencias, vivencias y realizaciones del pasado que ayudan a discernir y a valorar la obra de construir cotidianamente el mundo jurídico del derecho en la educación.

\section{Origen y Evolucion}

Tiene su origen en forma conjunta con la humanidad, porque el Derecho Educativo es la ciencia más antigua del mundo, ya que nació y creció con la humanidad, al producirse la interrelación de vivir en comunidad (derecho) y al educar los padres a sus hijos (educación).

El Derecho Educativo al igual que los derechos humanos tienen origen; no en el orden jurídico positivo que le otorga un "sistema establecido"; sino en el derecho natural universal.

Es por esto, que el reconocimiento del Derecho Educativo y los derechos humanos se fue materializando con el desarrollo espiritual de la humanidad.

Es decir, que al margen de ser reconocidos por el sistema de un aparato coactivo estatal o internacional, los principios del Derecho Educativo son universalmente válidos, independiente de su reconocimiento efectivo por ciertos sistemas, órganos o individuos

El Derecho Educativo es el principal derecho humano, ya que sin su ejercicio no se puede acceder al ejercicio de los restantes derechos humanos.

Siempre fue considerado en su concepción individual y lentamente fue evolucionando hasta llegar a las actuales concepciones universalistas, que hoy reconoce a los ciudadanos un derecho universal a la educación.

El Derecho Educativo ha sufrido esta evolución, ya que de ser considerado como un derecho individual a "aprender", del cual se desprendía el otro derecho individual de "enseñar"; fue evolucionando hasta ser reconocido universalmente entre el segundo 


\section{CIÊNCIAS HUMANAS}

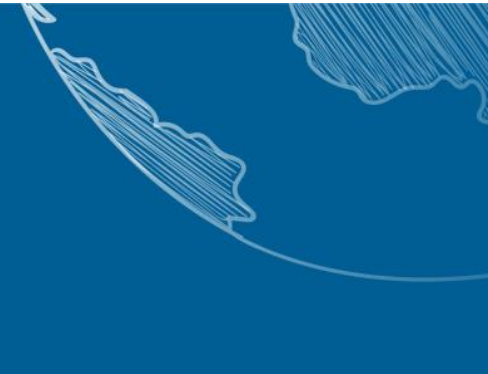

grupo de Derechos Humanos, que se refiere a los valores sociales, económicos y culturales.

El derecho es un componente esencial de las relaciones y de las estructuras sociales y factor principal en la resolución de los conflictos comunitarios. Es por esto que el derecho debe acompañar las transformaciones producidas en la sociedad y en la cultura contemporánea con una nueva cultura jurídica, que ayude a legitimar las normas vigentes.

La democracia y el derecho persiguen un mismo objetivo: la construcción social e individual de un proyecto humano cuyo instrumento es la educación. Es por ello que el derecho educativo en la escuela debe servir como instrumento de transformación social para alcanzar un mundo mejor.

El objetivo del Derecho Educativo en la comunidad escolar, es crear pautas normativas que faciliten el aprendizaje de una ciudadanía responsable y democrática, la cultura para la paz y los derechos humanos; al mismo tiempo que lograr una convivencia comunitaria, la prevención de la violencia y la resolución pacífica de los conflictos.

En definitiva es el Derecho Educativo el encargado de lograr que aumenten los factores de prevención y protección contra todo tipo de violencia, que se favorezca la convivencia a través de la regulación pacifica de los conflictos e inculcar conocimientos que coadyuven las actitudes, valores y comportamientos imprescindibles para la construcción de una ciudadanía responsable y la Cultura de Paz en la sociedad.

\section{Naturaleza y Fuentes}

El Derecho Educativo forma parte de la naturaleza humana y estuvo y está presente en el sentimiento jurídico de toda comunidad que se reúna en torno de una institución llamada escuela y en sus normas de convivencia, desde el origen mismo de la sociedad; aún mucho antes del nacimiento del estado como organización social.

Tanto en la legislación, como en las costumbres y/o en las decisiones judiciales, siempre encontramos vestigios del Derecho Educativo en actos concretos del hombre en la historia de la humanidad. 


\section{CIÊNCIAS HUMANAS}

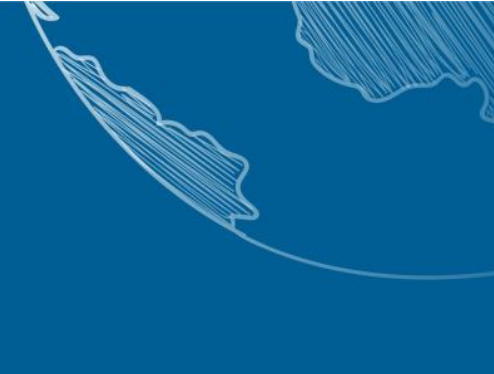

\section{Es natural y exigible}

Parece obvio que el hablar de Derecho Educativo nos estamos refiriendo a situaciones normativas escolares que están estipuladas en disposiciones del derecho positivo nacional y/o internacional.

El Derecho Educativo al igual que los derechos humanos tienen origen; no en el orden jurídico positivo que le otorga un "sistema establecido"; sino en el derecho natural universal.

Es por esto, que el reconocimiento del Derecho Educativo y los derechos humanos se fue materializando con el desarrollo espiritual de la humanidad.

Es decir, que al margen de ser reconocidos por el sistema de un aparato coactivo estatal o internacional, los principios del Derecho Educativo son universalmente válidos, independiente de su reconocimiento efectivo por ciertos sistemas, órganos o individuos.

A la altura del desarrollo y evolución de la humanidad, debemos abandonar el prejuicio esencialista de que debe haber un único concepto de derecho.

No todo derecho da a su titular la facultad de desobligar a quien tiene el deber correlativo, existen derechos irrenunciables, y en especial, derechos acerca de conductas que son a la vez el contenido de deberes, tal es el caso del Derecho Educativo.

Identificar a los derechos con intereses, es un dilema tradicional del derecho subjetivo materialista y consumista.

Los derechos individuales deben estar supeditados, para su validez y ejercicio, al bien común.

No deben tener validez todos aquellos derechos individuales y corporativos que constituyen restricciones u obstáculos a la prosecución del bien común.

El objeto del derecho tiene que ser algo que beneficie a la comunidad.

No basta que se trate de un derecho que sea correcto reconocer, o incorrecto privar a un individuo o corporación, para que sea el contenido de una norma, debe ser algo que se supone beneficioso a la comunidad.

Por ejemplo no puede un derecho gremial (corporativo) privar a la comunidad del derecho a la educación. 


\section{(1) URI|}

Un rasgo distintivo del Derecho Educativo y los derechos humanos es que ellos versan sobre principios naturales de fundamental importancia para la sociedad.

No existe derecho alguno por encima del Derecho Educativo, es el derecho de los derechos y es primordial para el ejercicio de los derechos humanos.

Conclusión: El Derecho Educativo tiene una importancia primordial para la sociedad actual. 